\title{
Comprehensive approach for strengthening the management of regional referral hospitals in Tanzania
}

\author{
Hisahiro Ishijima*1, Masashi Teshima ${ }^{1}$, Yasuko Kasahara ${ }^{1}$, Noriyuki Miyamoto' ${ }^{1}$. Fares Masaule ${ }^{2}$, Raynold John ${ }^{3}$ \\ ${ }^{1}$ Fujita Planning Co., Ltd., Tokyo, Japan \\ ${ }^{2}$ Regional Referral Hospital Management Project, Dar es Salaam, United Republic of Tanzania \\ ${ }^{3}$ Ministyr of Health, Community Development, Gender, Elderly and Children, Dodoma, United Republic of Tanzania
}

Received: September 9, 2020

DOI: $10.5430 /$ jha.v9n5p1
Accepted: September 30, 2020 Online Published: October 9, 2020

URL: https://doi.org/10.5430/jha.v9n5p1

\begin{abstract}
Hospital managers in Tanzania have always been expected to manage and deliver quality services to patients under resource constrained situation. In the organizational structure of regional referral hospitals (RRHs) in Tanzania, including, clinicians with very limited knowledge of and skills in management hold over $80 \%$ of the managerial positions. The Ministry of Health, Community Development, Gender, Elderly and Children of Tanzania has identified the strengthening of management at RRHs as a key to improving efficiency and effectiveness in health service delivery. The ministry launched a five-year project for strengthening hospital management in RRHs in collaboration with the Japan International Cooperation Agency. The project provided a series of training courses for capacitating RRH management Team (RRHMT), and developed and introduced several planning, monitoring, and evaluation tools. This study was conducted to identify the positive factors and approaches for strengthening management of RRHs. Necessary information and data were collected through the intervention and analyzed to measure the effectiveness of the interventions. RRHMT members obtained basic knowledge of and skills for hospital management through the project interventions with those deferent management tools to improve the completion of their hospital management tasks. Based on the findings, it can be concluded that the interventions were effective in strengthening the managerial capacity of RRHMTs. The study also confirmed that the strategy to improve hospital management was on the right track for improving health service delivery in efficient and effective manners. The lessons learned from the project can be adjusted for the management of lower healthcare facilities.
\end{abstract}

Key Words: Regional referral hospitals, Management development, Hospital management, Tanzania

\section{INTRODUCTION}

Within healthcare systems, hospitals play an important role to provide safe, quality healthcare services to the community in low-, middle-, and high-income countries; however, hospital organizations are becoming increasingly complex and difficult to operate without professional management. ${ }^{[1]}$ Effective and efficient hospital management is a major challenge, especially in low-income countries where health re- sources, such as human resources for health for delivering healthcare services and health commodities, are constrained. In low-income countries, public hospitals are the primary facilities that provide healthcare services; however, many studies identified that public hospitals in low-income countries are undermanaged due to insufficient knowledge and skills of hospital managers, and it is affecting the provision of healthcare services. ${ }^{[1-4]}$ Hospital-specific management

*Correspondence: Hisahiro Ishijima; Email: h.ishijima@fujita-plan.com; Address: Fujita Planning Co., Ltd., Tokyo, 102-0074, Japan. 
practices are strongly related to the quality of hospital patient care and productivity outcomes. ${ }^{[2]}$ Therefore, strengthening hospital management capabilities is an important strategy for improving healthcare delivery performance and the overall health system. ${ }^{[5]}$

\subsection{Hospital reform in Tanzania}

Similar situations have been observed in Tanzania where public hospitals utilized about 29 percent of total health expenditures in 2009/10, up from 11 percent in 2005/06. Public and faith-based hospitals consumed over two-and-ahalf times more health expenditures in absolute values in 2009/10 compared to 2005/06. ${ }^{[6]}$ With the majority of health expenditures in Tanzania being disbursed to hospitals, hospital management and the efficiency of hospital operations needs to be addressed to strengthen the country's healthcare system as a whole and to promote universal health coverage within the resource constraints.

The Ministry of Health and Social Welfare (MoHSW) - currently, the Ministry of Health, Community Development, Gender, Elderly and Children (MoHCDGEC) - of Tanzania introduced hospital reforms in 1997 as part of the health sector reform, and the hospital reform program was implemented from 1999 to 2009 . The idea behind the hospital reform program was to promote accountability, efficiency and effectiveness in the hospital management structure. In addition, it aimed to provide more authority to hospitals to mobilize resources and make decisions. ${ }^{[7]}$ During the hospital reform program, the structure of hospital management was reviewed, and hospital management teams were established as functional units, and a platform towards successful execution of hospital reforms was implemented. ${ }^{[8]}$ Training materials and management training workshops were also developed for capacitating healthcare managers during the program. ${ }^{[8]}$

Based on Shwekerela, ${ }^{[7]}$ negative effects of the reform, such as the creation of dual accountability to President OfficeRegional Administration and Local Government (PORALG) and Ministry of Health staff shifting from private to government, functional overlap between RRHMTs and RHMTs, were reported more than the positive effects. The study reported changes in management structure and lines of command; however, there seemed to be no evidence to support that hospital managers became more knowledgeable and skilled through the interventions implemented in the reform.

After the termination of the donor support, the hospital reform program was discontinued and hospital management and governance of RRHs were left far behind until the strengthening of RRHs was stated as one of the strategic objectives in the Health Sector Strategic Plan 4. ${ }^{\text {[9] }}$

\subsection{Issues in hospital manageemnt in Tanzania}

Despite the efforts and inputs made during the hospital reforms in Tanzania, RRHs have continued to face numerous challenges, right after hospital reforms were terminated in 2009. Since the termination of the hospital reform program, there has been scant investment in promoting hospital management to prepare them to assume decentralized roles and expanded autonomy. The following managerial issues in RRHs have been identified and reported through a baseline survey of the project: ${ }^{[10]}$

- Weak knowledge of hospital management and poor skills exhibited by hospital management team members.

- Low quality and unsafe practices in medicine distribution (improper application of Infection Prevention and Control measures, poor linkage to patients' needs and satisfaction, etc.).

- A shortage and mismanagement of health resources.

- Many shortcomings in human resources management.

\subsection{Regional referral hospital management project in Tanzania}

RRHs are secondary level public hospitals in Tanzania that face a number of challenges in hospital management. RRHs face a chronic shortage of resources, such as health financing, human resources for health (HRH), medical equipment, and supplies, which makes the provision of sufficient and quality health services difficult.

Improving hospital management of RRHs has been addressed by the Government of Tanzania since the onset of the health sector reforms which have continually been implemented through Health Sector Strategic Plans (HSSP). In the third HSSP (HSSP 3), the Government of Tanzania set eleven implementation strategies and strengthening the referral service was clearly mentioned in Strategy 2. ${ }^{[11]}$ Likewise, in Part 5 (Service Delivery) of HSSP 4 from 2015-2019, the government was committed to strengthening RRH by focusing on improvements in the quality of care and management. ${ }^{[9]}$

The action plan was committed to improving the quality of services at RRHs by improving hospital management, introducing quality improvement activities through the implementation of the Total Quality Management Framework, establishing quality improvement units in the RRHs, and strengthening hospital governance through Hospital Advisory Boards (HAB). To achieve the goals set in the action plan, MoHCDGEC launched a technical cooperation project 
called, "Technical Cooperation Project for Strengthening Tanzania" (hereinafter referred to as the "Regional Referral Hospital Management for Regional Referral Hospitals in Hospital Management Project" [RRHMP]) in collaboration with Japan International Cooperation Agency (JICA).

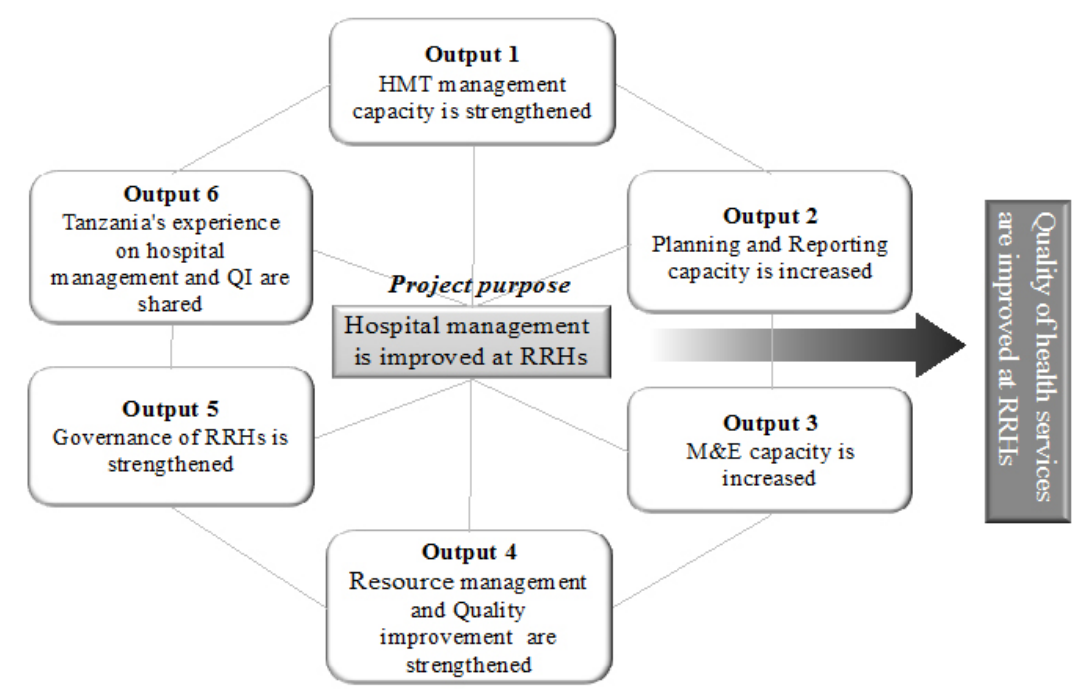

Figure 1. Expected outputs of the project

Table 1. Characteristics of RRHs

\begin{tabular}{|c|c|c|c|c|c|c|c|}
\hline \multirow[t]{2}{*}{ RRH } & \multirow{2}{*}{$\begin{array}{c}\text { Number of } \\
\text { staffs (Deficit) }\end{array}$} & \multirow[t]{2}{*}{ Bed capacity } & \multirow{2}{*}{$\begin{array}{c}\text { Number of } \\
\text { RRHMT members }\end{array}$} & \multicolumn{2}{|c|}{$\begin{array}{c}\text { Proportion of clinical and } \\
\text { administrative staff in RRHMT }\end{array}$} & \multirow{2}{*}{\multicolumn{2}{|c|}{$\begin{array}{l}\text { Number of members } \\
\text { trained on BHMT } \\
\text { and 5S-KAIZEN }\end{array}$}} \\
\hline & & & & Clinical & Admin. & & \\
\hline Temeke RRH & $457(5 \%)$ & 304 & 20 & 14 & 6 & 6 & $30 \%$ \\
\hline Katavi RRH & $202(58 \%)$ & 340 & 22 & 13 & 9 & 10 & $45 \%$ \\
\hline Sumbawanga RRH & $468(11 \%)$ & 217 & 24 & 8 & 16 & 5 & $21 \%$ \\
\hline Songwe RRH & $244(49 \%)$ & 150 & 15 & 6 & 9 & 11 & $73 \%$ \\
\hline Mbeya RRH & $325(32 \%)$ & 180 & 22 & 17 & 5 & 11 & $50 \%$ \\
\hline Njombe RRH & $109(77 \%)$ & 53 & 13 & 8 & 5 & 2 & $15 \%$ \\
\hline Songea RRH & $464(4 \%)$ & 321 & 15 & 5 & 10 & 10 & $67 \%$ \\
\hline Ligula RRH & $263(45 \%)$ & 228 & 22 & 18 & 4 & 10 & $45 \%$ \\
\hline Sokoine RRH & $260(46 \%)$ & 241 & 22 & 18 & 4 & 13 & $59 \%$ \\
\hline Mwananyamala RRH & $370(46 \%)$ & 254 & 15 & 9 & 6 & 12 & $80 \%$ \\
\hline Bombo RRH & $369(46 \%)$ & 424 & 14 & 6 & 8 & 7 & $50 \%$ \\
\hline Mawenzi RRH & $449(34 \%)$ & 210 & 18 & 10 & 8 & 5 & $28 \%$ \\
\hline Mt. Meru RRH & $475(30 \%)$ & 500 & 19 & 9 & 10 & 5 & $26 \%$ \\
\hline Manyara RRH & $208(69 \%)$ & 89 & 15 & 10 & 5 & 12 & $80 \%$ \\
\hline Singida RRH & $368(46 \%)$ & 275 & 15 & 10 & 5 & 10 & $67 \%$ \\
\hline Dodoma RRH & $476(30 \%)$ & 423 & 24 & 12 & 12 & 9 & $38 \%$ \\
\hline Iringa RRH & $403(41 \%)$ & 377 & 24 & 19 & 5 & 24 & $100 \%$ \\
\hline Morogoro RRH & $528(22 \%)$ & 450 & 15 & 9 & 6 & 7 & $47 \%$ \\
\hline Tumbi RRH & $389(17 \%)$ & 219 & 21 & 16 & 5 & 15 & $71 \%$ \\
\hline Amana RRH & $380(21 \%)$ & 340 & 20 & 14 & 6 & 10 & $50 \%$ \\
\hline Bukoba RRH & $284(41 \%)$ & 308 & 22 & 16 & 8 & 7 & $32 \%$ \\
\hline Sekou-Toure RRH & $362(25 \%)$ & 315 & 23 & 19 & 4 & 8 & $35 \%$ \\
\hline Geita RRH & $313(35 \%)$ & 207 & 17 & 9 & 8 & 7 & $41 \%$ \\
\hline Musoma RRH & $310(35 \%)$ & 269 & 25 & 11 & 14 & 10 & $40 \%$ \\
\hline Simiyu RRH & $137(72 \%)$ & 208 & 15 & 10 & 5 & 5 & $33 \%$ \\
\hline Shinyanga RRH & $309(36 \%)$ & 304 & 17 & 10 & 7 & 9 & $53 \%$ \\
\hline Kitete RRH & $347(28 \%)$ & 260 & 20 & 15 & 5 & 10 & $50 \%$ \\
\hline Maweni RRH & $245(49 \%)$ & 241 & 20 & 10 & 10 & 10 & $50 \%$ \\
\hline
\end{tabular}


Table 2. List of modules and sessions in BHMT

\begin{tabular}{|c|c|c|}
\hline Module & Session & Session title \\
\hline \multirow{3}{*}{$\begin{array}{l}\text { 1: Understanding RRHs } \\
\text { setting }\end{array}$} & Session 1 & The composition, roles and functions of various structures at National and regional level \\
\hline & Session 2 & Policies and Strategic Frameworks \\
\hline & Session 3 & The Context of Regional Referral Hospitals, existing operational challenges and missed opportunities \\
\hline \multirow{9}{*}{ 2: Basic Management } & Session 1 & Hospital Systems \\
\hline & Session 2 & Basic concept of Management \\
\hline & Session 3 & Effective Leadership \\
\hline & Session 4 & Principles of Delegation \\
\hline & Session 5 & Change management \\
\hline & Session 6 & Team Building \\
\hline & Session 7 & Communication in organization \\
\hline & Session 8 & Managing Meetings \\
\hline & Session 9 & Conflict and Conflict Management \\
\hline \multirow{8}{*}{ 3: HRH Management } & Session 1 & Basic Concepts of Human Resource Management \\
\hline & Session 2 & Human Resources Planning \\
\hline & Session 3 & Staffing \\
\hline & Session 4 & Staff induction \\
\hline & Session 5 & Performance Appraisal \\
\hline & Session 6 & Motivation \\
\hline & Session 7 & Supportive Supervision \\
\hline & Session 8 & HRHIS \\
\hline \multirow{3}{*}{$\begin{array}{l}\text { 4: Basic financial, } \\
\text { logistic and information } \\
\text { management }\end{array}$} & Session 1 & Hospital Information System and Records \\
\hline & Session 2 & Financial Management \\
\hline & Session 3 & Logistics Management \\
\hline \multirow{5}{*}{$\begin{array}{l}\text { 5: Quality and Safety of } \\
\text { Hospital services }\end{array}$} & Session 1 & Definition of Quality terms \\
\hline & Session 2 & QI activities in Tanzania \\
\hline & Session 3 & 5S-KAIZEN-TQM approach \\
\hline & Session 4 & Safety Improvement \\
\hline & Session 5 & Customer care and Client satisfaction \\
\hline
\end{tabular}

The project started in May 2015 and ended in May 2020 with the aim of strengthening the hospital management capacity of twenty-eight RRHs that are operated as secondary levels of public hospitals in twenty-six regions in the country. Figure 1 explains the logical framework of the project to achieve the project purpose: "Hospital management is improved at RRHs". The project set the following six outputs for strengthening certain areas: 1) Basic hospital management capacity of the RRHMT, 2) Planning and reporting capacity of the RRHMT, 3) Monitoring and evaluation of capacity, 4) Resource management and quality management capacity, 5) Governance, and 6) Sharing of good practices.

\subsection{Characteristics of RRHs}

As mentioned above, RRHs are operated as secondary level public hospitals in the healthcare system of Tanzania. Health services delivery at RRHs is governed by a Regional Referral
Hospital Advisory Board (RRHAB), which is endorsed by the MoHCDGEC, to ensure interests of the community on health issues are met. The RRHAB advises and oversees the performance of the RRH through the RRHMT. Table 1 shown explains the characteristics of 28 RRHs in the country.

\subsection{Interventions for strengthening hospital manage- ment in RRHs}

The following interventions were implemented during the project period to achieve the six outputs and project purpose in Figure 1.

\subsection{Basic hospital management training}

The first intervention was to capacitate the RRHMT members on basic hospital management. At the beginning of the project, a training needs assessment for the RRHMT was conducted to understand the managerial capacity of the 
RRHMT, to know what managerial knowledge and skills need development, and what kind of managerial training was demanded by RRHMT members.

The assessment results revealed that many RRHMT members had very little or no opportunity to attend management related training, and have been seeking opportunities to be trained in hospital management. Additionally, those RRHMT members were seeking technical mentorship while they were in service. Based on the findings from the assessment, the areas shown in Table 2 were identified as weaknesses of hospital managers and were to be developed as a module of basic hospital management training (BHMT). BHMT was conducted over six days to cover five modules, and an average of 11 RRHMT members from each RRH attended the training. ${ }^{[10]}$ In BHMT conducted in $2017,71 \%$ of participants were senior managers; however, in 2018, that proportion was reduced to $56 \%$.

\subsubsection{Introduction of planning and reporting tools to RRHMTS}

Comprehensive Hospital Operation Plan (CHOP) and Quarterly Progress Report (QPR) templates were developed for the standardization of planning and reporting procedures for RRHs. Previously, planning and budgeting activity was based on the compilation of demands from departments. The new CHOP was designed to strengthen the evidencebased planning approach at the department level to break through the old planning habits. The QPR template was developed for the RRHMT to submit quarterly reports to monitor the progress of implementing planned activities in the CHOP. Both the CHOP and QPR are assessed by the Ministry officials, and assessment results are reported back to the RRHMT. CHOP and QPR guidelines were developed and distributed to all RRHMTs. Orientation for CHOP and QPR development was conducted for RRHMTs. Key hospital managers, such as the hospital secretary and the director of hospital, were invited to the training twice to learn about the CHOP and QPR. Additionally, 31 key performance indicators (KPIs) for hospital management were identified, and RRHMTs were instructed to collect 42 data elements to calculate the KPIs to supplement the quarterly reports.

\subsubsection{Introduction of Monitoring Tools to RRHMTs}

An Internal Supportive Supervision (ISS) tool was developed and introduced to RRHMTs to strengthen the monitoring and evaluation of departmental performance in the hospitals. ISS was comprised of 78 check items in eight areas. RRHMTs are supposed to conduct ISS assessments every quarter to monitor department functions and the progress of the planned activities in the CHOP. The ISS report must be attached to the QPR and submitted to the MoHCDGEC for assessment. Orientation for ISS implementation was conducted for key hospital managers in RRHMTs, such as the director of hospital and the quality improvement officer.

\subsubsection{Introduction of Performance Assessment Tools to MoHCDGEC}

External Hospital Performance Assessment (EHPA) tools were developed and introduced to the MoHCDGEC for strengthening the evaluation of the performance of RRHs. EHPA tools, which are comprised of 109 check items in 12 areas, were used to collect necessary information and data from RRHMTs. The project organized EHPA facilitator training to educate and train the selected Ministry officials to make them competent assessors to implement EHPA in an effective manner. EHPA has been conducted once a year by EHPA assessors since 2017 . The collected data were compiled and analyzed, and the results were disseminated to RRHMTs for further improvement in their performances. EHPA has been conducted between August and September every year before planning and budgeting cycles start so that gaps and challenges identified from findings of the EHPA can be reflected as priorities in the next fiscal year (FY) CHOP.

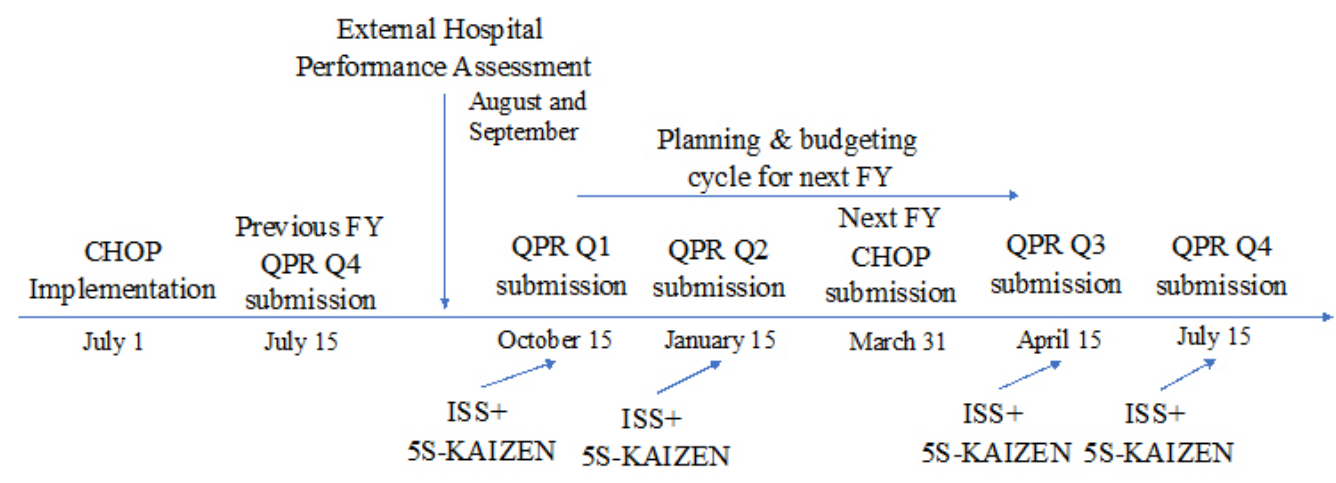

Figure 2. Annual hospital management activity flow in RRH 


\subsubsection{Quality improvement training and resource manage- ment}

To improve the quality of healthcare services and resource management in RRHs, the MoHCDGEC selected the 5SKAIZEN-TQM approach, and disseminated the approach to all RRHs. During the process of disseminating the 5SKAIZEN-TQM approach, RRHMT members and Quality Improvement Team members were selected to participate in the KAIZEN training. Then, trained personnel were asked to conduct in-house training to disseminate the 5S-KAIZENTQM approach within the hospital.

\subsubsection{Support for the establishment of a hospital gover- nance body}

The concept of having a hospital governance body was reviewed during the previous hospital reform and reintroduced to RRHs. The project supported the establishment of a hospital governance body, called a "Regional Referral Hospital Advisory Board (RRHAB)", through the development of guidelines for RRHAB establishment and operation, and trained RRHMTs on these matters. The above-mentioned interventions were implemented to improve the management capacity at RRHs as shown in Figure 3.

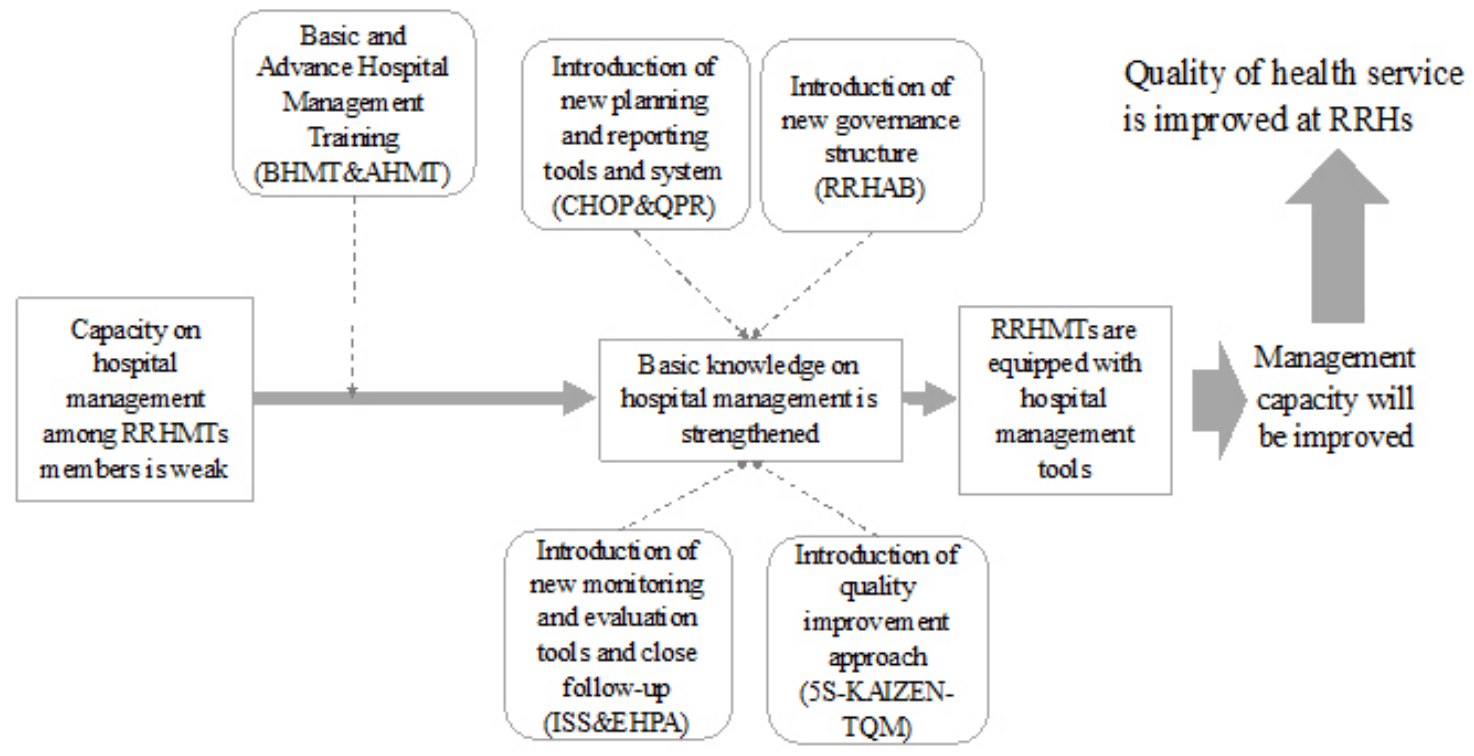

Figure 3. Hospital management improvement framework

\subsection{Rational and aim of the study}

Hospital management has been identified as a challenge for low- and middle-income countries. As examples, studies in Sub-Saharan Africa and South Africa reported improvement in clinical operation, work efficiency, and reduction of waiting time and congestion after addressing hospital management deficiencies. ${ }^{[4,12]}$ Strengthening hospital management has been slower to gain traction in low-income countries. There has been no study, to the authors' knowledge, conducted to look at strengthening hospital management of public hospitals on a large scale in Africa.

The overall aim of this study is to identify the effective factors and approaches for strengthening hospital management at RRHs in Tanzania, and then to draw on lessons from the project intervention to share with implementers aiming to strengthen hospital management in other low-income countries. Based on the conceptual framework, this study aims to answer the following questions: 1) Were the project in- terventions effective in improving managerial capacity of the hospital management team? 2) What were the positive factors that influenced the change management of RRHs?

\section{Methods}

In this case study, we adopted an exploratory case study design. The effectiveness of the project interventions was measured through the outputs of the interventions. Data studied were based on the rollout conceptual framework shown in Figure 3.

Information was extracted from the BHMT pre- and postassessment report from 2017 and 2018, CHOP assessment reports from 2017 to 2019, QPR assessment reports from 2017 to 2019, EHPA reports from 2017 to 2019, and consultation visit reports from 2017 to 2019. The effectiveness of the BHMT was measured by calculating the effect size (d) for $t$ test, based on the results of pre- and post-training assessments conducted during the BHMT in 2017 and 2018. Effect 
size (d) is calculated from the average of the post-training assessment scores minus the average of the pre-training assessment scores divided by the standard deviation of the two conditions. ${ }^{[13,14]}$ To comprehensively examine the impact of project interventions on strengthening hospital management, the following analysis was performed.

- Differences in the BHMT pre- and post-assessment in transferring knowledge to hospital management.

- Transition of the CHOP average score to see the planning capacity improvement of RRHMTs.

- Differences in the EHPA average score based on the improvement of the CHOP average score.

- Relationship between the BHMT post-assessment score and CHOP and QPR assessment scores for understanding how management knowledge and skills influences the planning, monitoring of operations, and reporting.

- Transition of the EHPA average score to see the performance of the RRHMTs.

- Linkage between ISS scores and EHPA scores from 2017-2019.

- Linkage between Quality Improvement Team (QIT) functions and EHPA scores from 2017-2019.

- Linkage between HAB establishment and functions with CHOP and EHPA scores from 2017-2018.

\section{RESULTS}

\subsection{Managerial capacity buiilding of RRHMT members through BHMT}

Figure 4 shows the box plot with a rotated Kernel density plot on each side (violin plot). The vertical axis shows the scores of participants in pre- and post-test of BHMT for health managers in RRHMTs. As shown in Table 3, Comparing pre-test and post-test scores of participants in BHMT shows a significant increase $(p<.001)$ with the effect size (Cohen's $d$ ) of 1.58. This result indicated that the effect of this training achieved a moderate level. ${ }^{[15]}$ Although the distribution of scores did not change between the pre-test and post-test, some higher score outliers were observed in the post-test. This implies the training contributed to an overall raising of participants' knowledge and that some participants obtained higher levels knowledge through this training.

Table 3. Effectiveness of BHMT

\begin{tabular}{lll}
\hline & Pre-test & Post-test \\
\hline Number of valid responses & 303 & 302 \\
Mean $(S D)$ & $28.7(4.3)$ & $34.2(5.3)$ \\
Effect size (Cohen's $d)$ & 1.12 & \\
Wilcoxon signed rank test & $p$-value $<.001$ & \\
\hline
\end{tabular}

Average individual scores of the post-tests in BHMT by RRHMT members were treated as the knowledge level on management of RRHMTs. The distribution of the management knowledge level of RRHs is shown in Figure 4. Although there was a limitation based on the small sample size, the distribution of the management knowledge seems to be biased for each RRH.

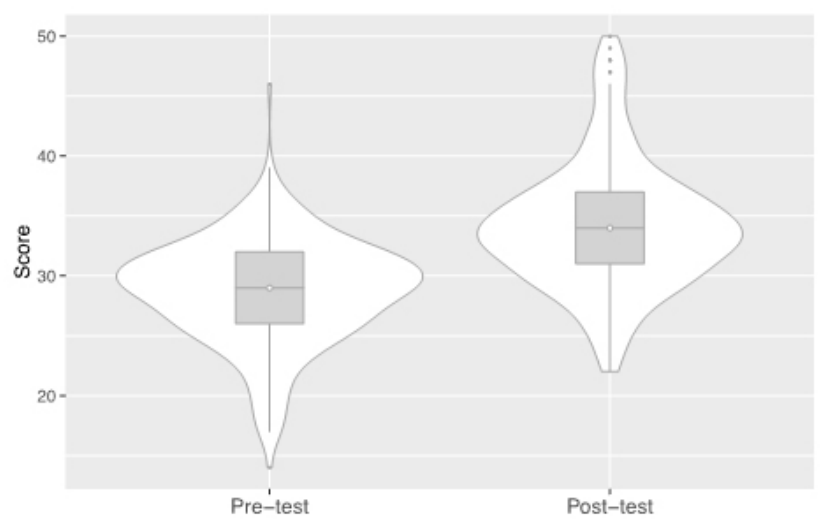

Figure 4. Box plot of scores of BHMT pre- and post-test by individual

\subsection{Continuous variable vs. categorial variables}

The maximum BHMT score among individuals within each RRH was treated as the RRH's BHMT score. BHMT, ISS, and $\mathrm{CHOP}$ scores are divided into low or high categories by medians. Figure 5 shows the EHPA median score with interquartile range (IQR) by the categories of BHMT, ISS, and CHOP. High BHMT score groups and high ISS score groups show significantly high EHPA scores. As shown in Table 4, statistical significance was not observed between EHPA and BHMT or between ISS and CHOP; however, hospitals that showed high scores on BHMT and ISS tended to show high scores on EHPA.

As shown in Table 5 and Figure 6, statistical significance was not observed between BHMT and ISS or between BHMT and CHOP; however, hospitals that showed high scores on BHMT tended to show high scores on ISS and CHOP.

Table 4. EHPA scores by categorical variables

\begin{tabular}{lccc}
\hline \multicolumn{2}{l}{ Categories } & Median score of EHPA (IQR) & $\boldsymbol{p}_{\text {-value }}^{\dagger}$ \\
\hline \multirow{2}{*}{ BHMT } & Low & $68.1(6.1)$ & \\
& High & $80.3(11.4)$ & 0.006 \\
\multirow{2}{*}{ ISS } & Low & $67.9(7.9)$ & \multirow{2}{*}{0.014} \\
& High & $76.6(13.1)$ & \\
\multirow{2}{*}{ CHOP } & Low & $70.6(10.8)$ & 0.837 \\
\hline Note & High & $74.4(13.4)$ &
\end{tabular}



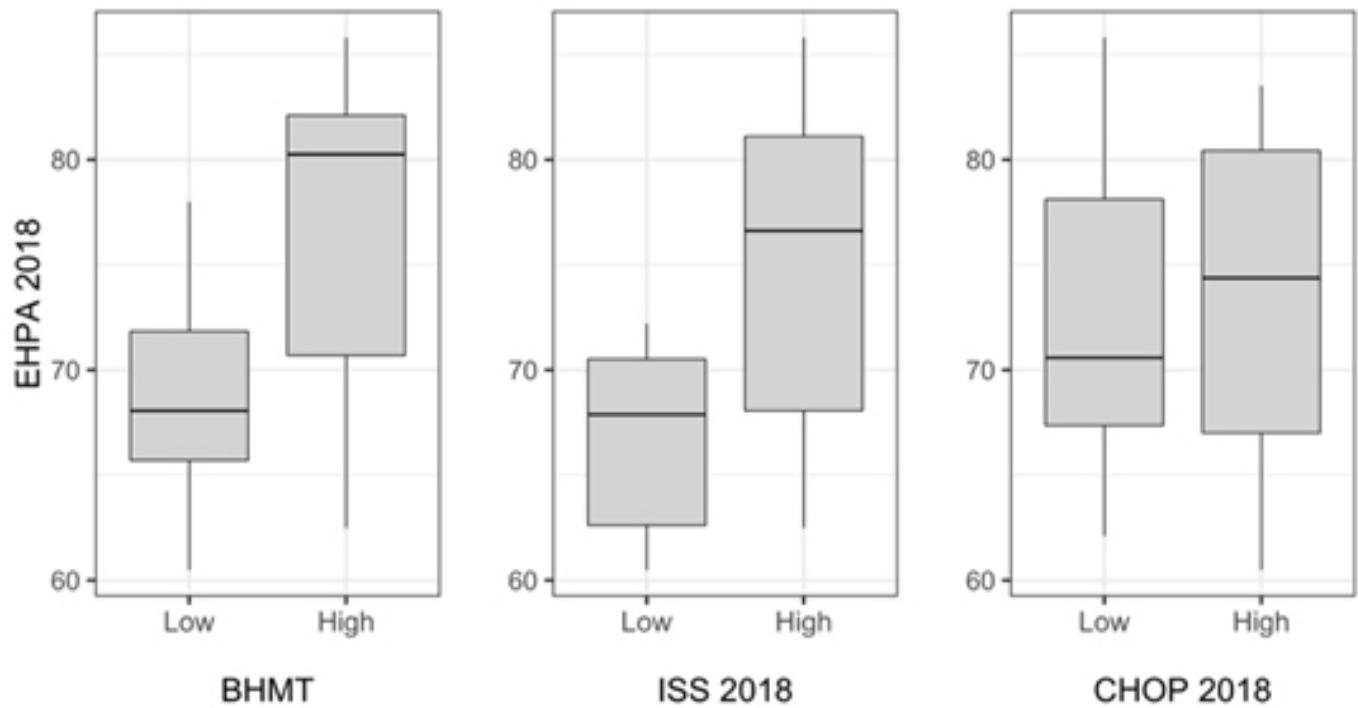

Figure 5. EHPA scores by categorical variables
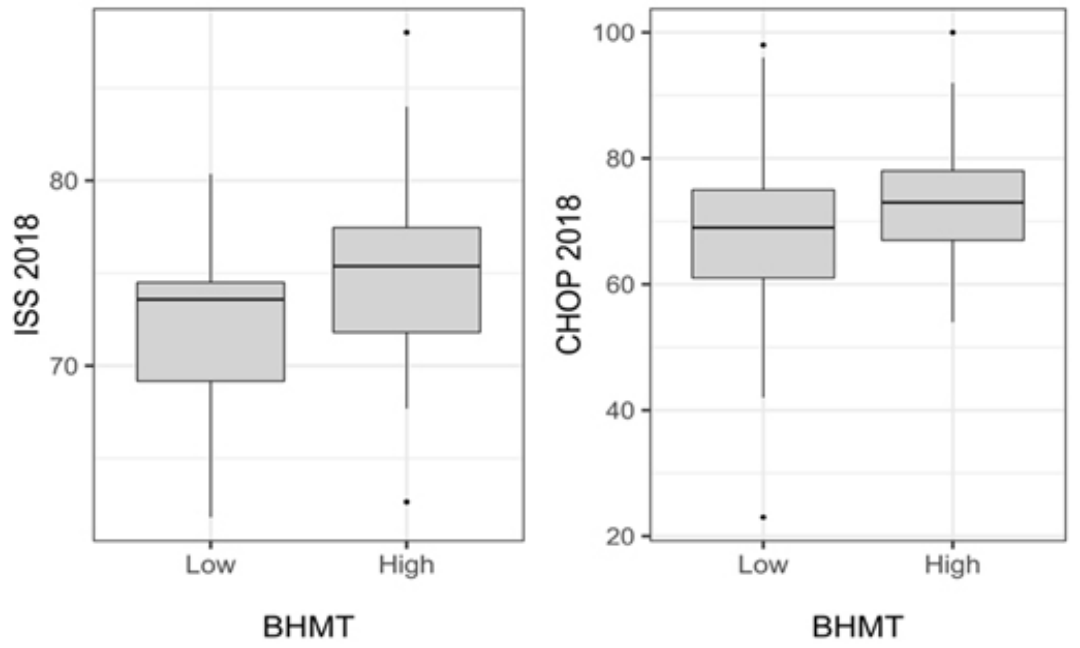

Figure 6. ISS and CHOP scores by BHMT

Table 5. EHPA scores by categorical variables

\begin{tabular}{llcccc}
\hline Categories & & Median score (IQR) of ISS & $\boldsymbol{p}$-value $^{\dagger}$ & Median score (IQR) of CHOP & $\boldsymbol{p}_{\text {-value }}^{\dagger}$ \\
\hline \multirow{2}{*}{ BHMT } & Low & $73.6(5.3)$ & & $69.0(14.0)$ & \\
& High & $75.4(5.7)$ & 0.160 & $73.0(11.0)$ & .368 \\
\hline
\end{tabular}

Note. ${ }^{\dagger}$ Wilcoxon rank sum test

\subsection{Planning and managerial capacity building of RRHMT members}

\subsubsection{CHOP average score from 2017-2019}

The transition of CHOP average scores is shown in Figure 7. The 2017 CHOP scored high because the assessment criteria were too simple and it was the first time for the assessors to conduct the assessment of CHOP. Therefore, CHOP assessment criteria were reviewed for 2018. Comparing the average CHOP scores in 2018 and 2019, although the score has not improved significantly, the variation in the CHOP score among RRHs became smaller, which indicates an improvement in the quality of CHOP. 


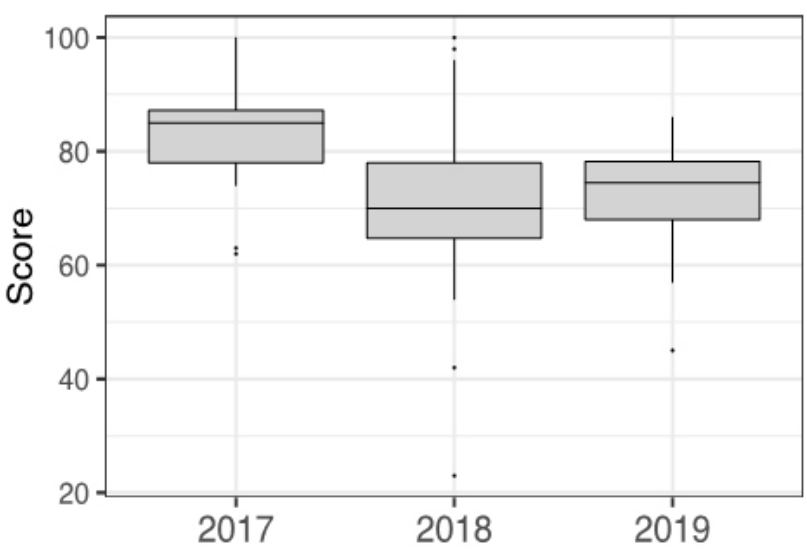

Figure 7. Transition of CHOP average score from 2017 to 2019

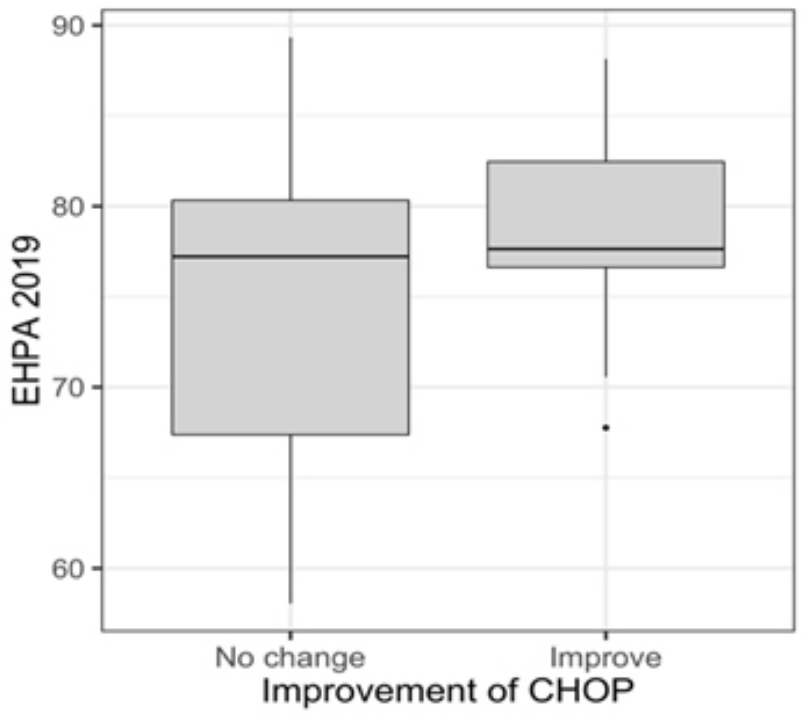

Figure 8. Differences in EHPA score based on the improvement of CHOP score

\subsubsection{Differences in EHPA average scores based on the improvement of sverage CHOP scores}

RRHs were categorized into two groups: 1) RRHs that improved the average CHOP score compared to 2018, and 2) RRHs that could not improve the average CHOP score or had no changes compared to 2018. Statistical significance was not observed as shown in Table 6; however, as shown in Figure 8, RRHs that improved the average CHOP score compared to the previous year also improved the average score of EHPA.

\subsection{Monitoring and evaluation capacity building of RRHMT members}

Figure 9 shows the transition of EHPA average scores from 2017-2019. Statistical significance was observed among EHPA average scores $(p<.001)$. The EHPA average score has improved from 66.3 in EHPA 2017 to 77.6 in EHPA 2019. In addition, the standard deviation decreased between 2017 and 2019. This indicates that the overall performance of RRHs has improved.

Table 6. Differences in EHPA score based on the improvement of CHOP score

\begin{tabular}{lllc}
\hline \multicolumn{2}{l}{ Categories } & $\begin{array}{c}\text { Median score (IQR) } \\
\text { of CHOP 2019 }\end{array}$ & $\boldsymbol{p}^{\text {-value }}$-v $^{\dagger}$ \\
\hline \multirow{2}{*}{ CHOP $\quad 2019<2018$} & $77.2(13.0)$ & \\
\hline Note $^{\dagger}$ Wilcoxon rank sum test & $77.6(5.8)$ & .191 \\
\hline
\end{tabular}

Note. ${ }^{\dagger}$ Wilcoxon rank sum test

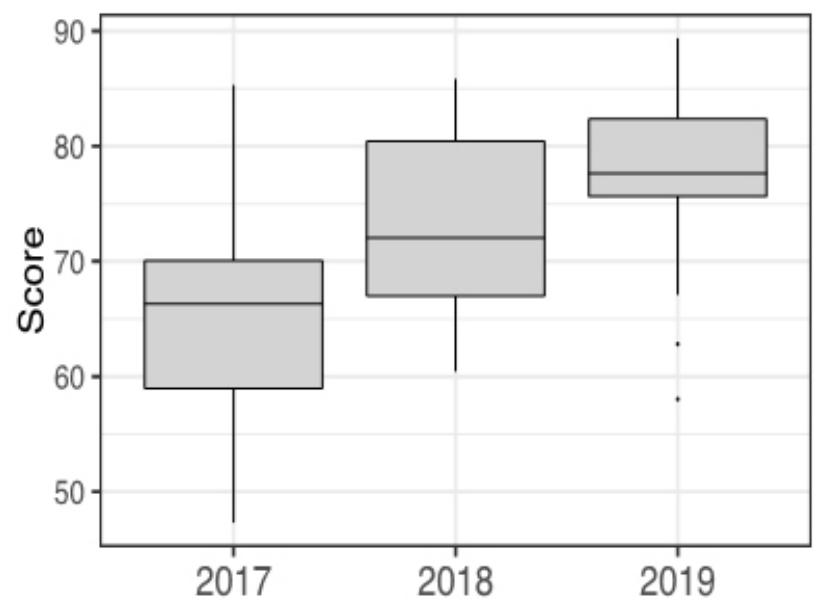

Figure 9. Transition of EHPA average score from 2017 to 2019

\subsection{Quality management capacity building of RRHMT members}

As shown in Table 7 and Figure 10, the function of the Quality Improvement Team improved from 2017 to 2018. Based on the QIT function score, RRHs were divided into the following two groups: 1) With a cut-off value of 60 or more, and 2) With a cut-off value of less than 60. The group that scored more than 60 in 2017 had a significantly higher score in EHPA 2019. Similarly, the group that scored more than 60 in re-evaluation of the QIT function in 2018 scored significantly higher EHPA scores in 2019. As mentioned in many studies, ${ }^{[16-18]}$ this finding indicated that the introduction of the team approach and the strengthening of the QI implementation structure are one of the important factors for quality management. 


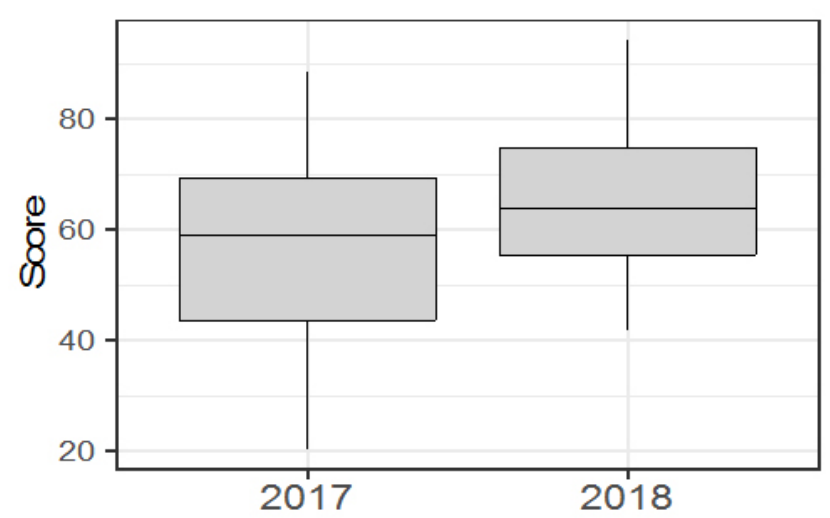

Figure 10. Transition of EHPA average score from 2017 to 2019

3.6 Linkage between hospital governing body and quality of CHOP/hosptial performance

As shown in Tables 8 and 9, the establishment of the Hospital Advisory Board (HAB) does not necessarily directly affect RRHMT's planning capacity and hospital performance.
However, only a few years have passed since the HAB was established at each RRH, and there is a possibility that the HAB members are not familiar with their tasks and may not be able to perform fully. Thus, it cannot be determined at this time that the HAB is not valid for strengthening hospital management.

\section{Discussion}

The hospital reform implemented in Tanzania from 1999 to 2009 has caused a major change in the management structure, with ownership of the RRHs being transferred from the Ministry of Health to PORALG. Management training has been conducted for hospital managers; however, there have been reports that more negative effects were observed over positive effects. ${ }^{[7,8]}$ On the other hand, all planned activities were effectively implemented in this project, and the majority of RRHs experienced improvement in hospital management through the strengthening of planning and reporting, monitoring and evaluation skills, and performance.

Table 7. Linkage between QIT function score and EHPA score

\begin{tabular}{|c|c|c|c|c|c|c|c|}
\hline & & \multicolumn{2}{|c|}{ EHPA 2017} & \multicolumn{2}{|c|}{ EHPA 2018} & \multicolumn{2}{|c|}{ EHPA 2019} \\
\hline & & Median (IQR) & $p$-value & score (IQR) & $p$-value & score (IQR) & $p$-value \\
\hline \multirow{2}{*}{ QIT 2017} & Low & $66.3(10.3)$ & & $71.3(9.5)$ & & $76.9(12.1)$ & \\
\hline & High & $65.9(12.6)$ & .3965 & 78.8 (15.0) & .1592 & $81.4(5.4)$ & .0257 \\
\hline \multirow{2}{*}{ QIT 2018} & Low & & & $70.6(7.9)$ & & $75.7(10.4)$ & \\
\hline & High & & & $76.9(13.8)$ & .1457 & 80.4 (5.7) & .0257 \\
\hline
\end{tabular}

Table 8. Linkage between HAB establishment and quality of CHOP

\begin{tabular}{|c|c|c|c|c|c|c|}
\hline & $\begin{array}{c}2017 \text { CHOP } \\
\text { (IQR) }\end{array}$ & $p$-value & $\begin{array}{c}2018 \text { CHOP } \\
\text { (IQR) }\end{array}$ & $p$-value & $\begin{array}{c}2019 \text { CHOP } \\
\text { (IQR) }\end{array}$ & $p$-value \\
\hline HAB not established & $85.0(5.0)$ & & $63.5(15.8)$ & & $75.0(12.5)$ & \\
\hline HAB established & $85.7(9.8)$ & .8663 & $72.0(8.8)$ & .1186 & $74.0(8.8)$ & .9426 \\
\hline
\end{tabular}

Table 9. Linkage between $\mathrm{HAB}$ establishment and hospital performance

\begin{tabular}{|c|c|c|c|c|c|c|}
\hline & $\begin{array}{c}2017 \text { CHOP } \\
\text { (IQR) }\end{array}$ & $p$-value & $\begin{array}{c}2018 \text { CHOP } \\
\text { (IQR) }\end{array}$ & $p$-value & $\begin{array}{c}2019 \text { CHOP } \\
\text { (IQR) }\end{array}$ & $p$-value \\
\hline HAB not established & $59.6(16.1)$ & & $69.5(16.7)$ & & $76.7(6.2)$ & \\
\hline HAB established & $67.8(8.6)$ & .1909 & $72.5(10.9)$ & .9063 & $79.9(5.2)$ & .4642 \\
\hline
\end{tabular}

We have learned several lessons through the implementation of the project activities. First of all, the existence of different levels of hospitals in the health system does not mean that public health facilities are operated systematically. Rabbani's study mentioned that health professionals who lack any prior management training are posted as health managers at hospital. ${ }^{[5]}$ This situation matches our experiences during the project period. The findings from the training needs assess- 
ment for RRHMTs, which was conducted in 2015 by the project, revealed that many respondents of the survey think they were not competent enough to manage their hospitals efficiently, and they needed hospital management training. ${ }^{[19]}$

There was no mechanism for educating managers in the public sector on hospital management in the country, and the majority of RRHMT members had no opportunity to learn basic knowledge before being posted as hospital managers. As pointed out and verified in other studies, ${ }^{[20-22]}$ we strongly agree that it is important and necessary to start hospital management education and training for health professions in order to strengthen hospital management.

The development of effective training courses and educational materials will require conducting appropriate training needs assessments and knowing the current state of the hospital management; then, it will be necessary to conduct a proper analysis of the obtained information and data. The implementation of the BHMT has been following these procedures exactly. Training materials, (BHMT participant manuals and facilitator guides) have been developed based on an assessment of training needs and issues identified during pilot training. In addition, BHMT instructors have been sharing information, reviewing the content of each training course, and improving their teaching methods and skills. We think these activities were useful for improving the knowledge and skills related to hospital management.

The increase in the CHOP and QPR assessment scores from 2018 to 2019 indicates the improvement in the quality of RRHMT planning and reporting capabilities. The reasons behind the improvement are probably the modification of the $\mathrm{CHOP} / \mathrm{QPR}$ guidelines and planning/reporting changes to a more user-friendly format. Moreover, RRHMTs are able to identify their planning and reporting weaknesses from the feedback of the assessment results and can take corrective action.

It is also revealed that RRHMTs need to be equipped with effective and efficient management tools. The tools for planning, reporting, and internal monitoring are very important for transferring management principles obtained from the training to actual management of hospitals. Those tools must be user friendly and have clear and standardized guidelines. Moreover, how to use the tools and the benefits of using those tools must be explained to RRHMTs. Otherwise, those tools are not going to be utilized and hospital managers might use their own way to operate the hospital rather than following the guidelines. Also, even if all RRHMTs have the same training opportunities, the degree of management capacity improvement can vary from hospital to hospital. The gap in management capacity between hospitals could be influenced by the composition of RRHMTs, and how trained personnel share the obtained knowledge and skills to other managers who could not attend the trainings. Therefore, trends of the performance of RRHs need to be monitored by using reports, external assessments, etc. If hospitals were showing poor performance continuously, it is necessary to conduct followup visits, conduct situation analysis to see the bottle necks, and provide technical support.

Based on the above discussion, the following positive factors are deemed to influence the success of hospital management through the intervention of the project:

- Sharing the results of monitoring and evaluation of QPR, ISS, EHPA, etc. among RRHs will stimulate competitiveness among hospitals in a positive manner. By doing so, RRHMTs will know their own status and continually strive to improve their situation.

- Poorly performing hospitals try to learn from good performing hospitals to improve their performance.

- Regular dialogue between the Ministry of Health and the hospitals to share issues will accelerate the coordination of different activities.

- Development and dissemination of guidelines will technically support RRHMTs in a standardized manner.

- Deployment of hospital policy and strategy to each department and section facilitates the cooperative operation of the hospital as one team. This will strengthen the departmental functions in the organization and lead to the achievement of organizational optimization.

Finally, the following issues may not be directly related to project intervention, but are experiences from the implementation of the project worth mentioning. During the project period, we recognized the rejuvenation of RRHMT members and the generational change in human resources. The authors guess that health sector reform, which was introduced in 1990s, is one of the reasons behind this change. During the early stage of health sector reform, a number of young civil servants were dismissed, which resulted in a reduction in civil servants. Thirty years have passed and the staff that were in their thirties at that time are nearing retirement age in their sixties. There are few staff in their fifties, who are supposed to be the successors to the retired employees, because many of them were dismissed because of the sector reform thirty years ago. These human resource decisions from the past have resulted in generational changes in RRHMTs in many hospitals with staff in their 30s and 40s becoming hospital managers because of their educational background. However, this demographic is not experienced in the management of hospitals and has little opportunity 
to learn about hospital management, which affects the low performance of the hospitals. It may take ten years for a manager in this age bracket to have enough experience to become a leader or manager. In addition, since the proper operation and management of public hospitals in low-income countries will greatly affect the quality of healthcare systems in those countries, it is important to continuously train and provide technical support to hospital managers.

Aimed at improving RRHs hospital management skills, this project gathered a lot of data from various interventions over an extended time period, and it is difficult to mention all information in this manuscript. Therefore, more detailed information on the project interventions is available in the references and guidelines listed in Further Reading.

\section{Conclusions}

This study examined the effectiveness of the series of interventions of the project for strengthening the management of public hospitals in Tanzania. The findings highlighted several positive factors that influence hospital management. From the different evidence obtained from the project activities in six outputs, we can conclude that the interventions from the project were useful for strengthening hospital management in RRHs in Tanzania. The BHMT was very useful for RRHMT members, who had little opportunity to obtain knowledge and skills on hospital management, to operate RRHs. However, it was clarified that gaining knowledge through hospital management training was just an entry point for improving their management skills. Hospital managers need to have effective and efficient management tools, and establish proper monitoring and evaluation mechanisms. Additionally, appropriate technical support must be provided from the central Ministry to ensure the quality of management and services. We hope this study will be useful in bringing these approaches to other levels of health facilities in Tanzania, as well as to other countries aiming to strengthen the management of health facilities.

\section{ACKNOWLEDGEMENTS}

The authors thank all who contributed to completing this study, especially the Directorate of Policy and Planning, MoHCDGEC in Tanzania. Without their strong support, it would not have been possible to implement the project activities related to hospital management through a series of interventions, including training of trainers and consultation visits. The authors would also like to give special thanks to the Japan International Cooperation Agency (JICA) for funding the Regional Referral Hospital Management Project in Tanzania.

\section{Conflicts of InTEREST Disclosure}

The authors declare they have no conflicts of interest.

\section{REFERENCES}

[1] Farida, Zainal F, Bambang AN, et al. Improving Local Hospital Management towards Sustainable Hospital in Developing Countries. The Leaderships Aspect and Organization Management. 2016; 5(1): 26-30.

[2] Khadka DK, Gurung M, Chaulagain N. Managerial competencies - A survey of hospital managers' working in Kathmandu valley, Nepal. J Hosp Adm [Internet]. 2014 Oct 11; 3(1): 62. https: //doi.org/10.5430/jha.v3n1p62

[3] Barati O, Sadeghi A, Khammarnia M, et al. A Qualitative Study to Identify Skills and Competency Required for Hospital Managers. Electron physician [Internet]. 2016 Jun; 8(6): 2458-65. PMid: 27504159. https://doi.org/10.19082/2458

[4] Fusheini A, Eyles J, Goudge J. The state of public hospital governance and management in a South African hospital: A case study. Int J Healthc [Internet]. 2017 Oct 12; 3(2): 68. https : //doi.org/10.5430/ijh.v3n2p68

[5] Rabbani F, Hashmani FN, Mukhi AAA, et al. Hospital management training for the Eastern Mediterranean Region: time for a change? J Health Organ Manag [Internet]. 2015; 29(7): 965-72. PMid: 26556162.https://doi .org/10.1108/JHOM-11-2014-0197

[6] Ministy of Health and Social Welfare. National Health Accounts (Year 2010) with sub-accounts for HIV and AIDS, Malaria, Reproductive and Child Health [Internet]. Dar es
Salaam, United Republic of Tanzania; 2012. Available from: https://www.hfgproject.org/wp-content/uploads/2015/ 02/Tanzania-National-Health-Accounts-Year-2010-wit h-Sub-Accounts-for-HIV-and-AIDS-Malaria-Reproduct ive-and-Child-Health.pdf

[7] Shwekerela B. The effects of hospital reforms on the management of public hospitals in Tanzania: Challenges and lessons learnt. World Hosp Health Serv [Internet]. 2014; 50(4): 23-6. Available from: http://www.ncbi.nlm.nih.gov/pubmed/25985557

[8] Ministry of Health and Social Welfare. Training modules on Management of district and regional referral hospitals; Module one; Management of hospital services. United Republic of Tanzania; 2010.

[9] Ministry of Health and Social Welfare. Health Sector Strategic Plan IV (2015-2020). United Republic of Tanzania; 2015.

[10] Regional Referral Hospital Management Project. Report on Baseline Survey for Hospital Management at Regional Referral Hospital. United Republic of Tanzania; 2015.

[11] Ministry of Health and Social Welfare. Health Sector Strategic Plan III 2009-2015. United Republic of Tanzania; 2009.

[12] Funk LM, Conley DM, Berry WR, et al. Hospital Management Practices and Availability of Surgery in Sub-Saharan Africa: A Pilot Study of Three Hospitals. World J Surg [Internet]. 2013 Nov 14; 37(11): 2520-8. PMid: 23942530. https://doi.org/10.1007/ s00268-013-2172-9 
[13] Thalheimer W, Cook S. How to calculate effect sizes from published research: a simplified methodology. Work-Learning Research Publication. 2002.

[14] Becker L. Effect size calculator [Internet]. University of Colorado, Colorado Springs. 1998 [cited 2013 Sep 17]. Available from: https : //1becker.uccs.edu/

[15] Christopher JF. An effect size primer: A guide for clinicians and researchers. Prof Psychol Res Pract [Internet]. 2009 Oct; 40(5): 532-8. https://doi.org/10.1037/a0015808

[16] Santana C, Curry LA, Nembhard IM, et al. Behaviors of successful interdisciplinary hospital quality improvement teams. J Hosp Med [Internet]. 2011 Nov; 6(9): 501-6. PMid: 22042750. https: //doi.org/10.1002/jhm.927

[17] Rowland P, Lising D, Sinclair L, et al. Team dynamics within quality improvement teams: a scoping review. Int J Qual Heal care J Int Soc Qual Heal Care [Internet]. 2018 Jul 1; 30(6): 416-22. PMid: 29617795. https://doi.org/10.1093/intqhc/mzy045
[18] Dixon N, Wellsteed L. Effects of team-based quality improvement learning on two teams providing dementia care. BMJ open Qual [Internet]. 2019; 8(2): e000500. PMid: 31259282. https: //doi.org/10.1136/bmjoq-2018-000500

[19] Regional Referral Hospital Hospital Management Project. Training Need Assessment Report for RRHs. United Republic of Tanzania; 2015.

[20] Kebede S, Abebe Y, Wolde M, et al. Educating leaders in hospital management: a new model in Sub-Saharan Africa. Int J Qual Heal care J Int Soc Qual Heal Care [Internet]. 2010 Feb; 22(1): 39-43. PMid: 19951963. https://doi.org/10.1093/intqhc/mzp051

[21] Terzic-Supic Z, Bjegovic-Mikanovic V, Vukovic D, et al. Training hospital managers for strategic planning and management: a prospective study. BMC Med Educ [Internet]. 2015 Feb 26; 15: 25. PMid: 25889166. https://doi.org/10.1186/s12909-015-0310-9

[22] Naidoo S, Mothagae M, Kistnasamy B, et al. A hospital-management training programme in South Africa. South African J Public Heal. 2017; 2(2): 34-9. 